\title{
Amanita smithiana Mushroom Ingestion: A Case of Delayed Renal Failure and Literature Review
}

\author{
Patrick L. West, MDa , Janet Lindgren ${ }^{b}$, B. Zane Horowitz, MD
}

aOregon Health and Science University, Oregon Poison Center

bOregon Mycological Society

\begin{abstract}
Introduction: In the Pacific Northwest a new pattern of mushroom ingestion has emerged, attributed to Amanita smithiana, in which renal failure has been the predominant manifestation.

Case Report: A 55-year-old male ate 3 raw wild mushrooms in a salad and had onset of severe nausea and vomiting within 6 hours. His vital signs were unremarkable. His labs were significant for a BUN of $14 \mathrm{mg} / \mathrm{dL}(5.0 \mathrm{mmol} / \mathrm{L})$, and a creatinine of $1.0 \mathrm{mg} / \mathrm{dL}$ (88umol/L), transaminases were elevated with an AST of $56 \mathrm{U} / \mathrm{L}$ (nl 9-40) and an ALT of $131 \mathrm{U} / \mathrm{L}$ (nl 14-72). Treatment was initiated with N-acetyl cysteine, penicillin, and milk thistle extract on the presumption that this was an amanitin-toxin containing mushroom. He developed acute renal failure that was not responsive to our treatment. Dialysis started on day 4 with a creatinine of $6.5 \mathrm{mg} / \mathrm{dL}$, which peaked on day 7 at $10.2 \mathrm{mg} / \mathrm{dL}$. We were able to obtain a positive mushroom identification by a mycologist as Amanita smithiana. The patient was discharged from the hospital for outpatient dialysis on day 10 and dialysis catheter was removed 39 days after ingestion with a creatinine of $1.4 \mathrm{mg} / \mathrm{dL}(123.8 \mathrm{umol} / \mathrm{L})$.

Discussion: Amanita smithiana mushroom poisoning presents within 6 hours of ingestion with GI toxicity, and develops delayed onset of renal insufficiency over the first 1 to 4 days. The early hospitalization of this case allowed a profile of the onset of liver and renal injury. Mild elevation of hepatic transaminases occurred on presentation and peaked 24 hours after the ingestion. Renal injury was detected 1 day after presentation, and progressed to require hemodialysis by 4 days postingestion. This pattern of delayed-onset renal toxic mushroom ingestion is emerging among mushroom ingestions in Western North America.
\end{abstract}

\section{INTRODUCTION}

Mushroom exposures are a common exposure confronting poison centers and emergency physicians, but despite the frequency, it is often difficult to discern which cases will have a benign clinical course and which may lead to organ failure. Analysis of the American Association of Poison Control Centers (AAPCC) data from 2003-2006 shows 31,145 (7786/year) mushroom ingestions, of which 13,426 (3357/year) were seen in a healthcare facility [1-4]. Of those seen in a healthcare facility, $12.5 \%$ are defined as having moderate or severe toxicity, and ultimately 21 (5/year) deaths occurred over this span [1-4]. The amatoxin-containing species of mushroom, the most common of which is Amanita phalloides, is responsible for over $90 \%$ of fatalities worldwide $[5,6]$.
Though A phalloides is the most common toxic mushroom ingestion worldwide, another-Amanita smithiana, a common mushroom in the Pacific Northwest with a different and serious toxicological profile-has been reported recently. The literature on A smithiana ingestions frequently does not have mycological confirmation, and presents limited data on the time course and laboratory progression of its toxicity, which has made identification of these ingestions difficult. We describe a case of $A$ smithiana mushroom ingestion, with an early presentation, mycological confirmation, and for which a thorough inpatient evaluation (including daily laboratory determinations of renal and hepatic function) are presented, which describes its unique time course of toxicity in much greater detail than is currently available in the literature. The available literature on A smithiana is reviewed to

Keywords: Amanita smithiana; renal failure; dialysis; mushroom ingestion

Notes: There was no outside funding of any kind used for this study.

Corresponding Author: Patrick West, MD, 3181 SW Sam Jackson Park Road, CB 550, Portland, OR 97239. E-mail: westp@ohsu.edu 
better characterize the time course, laboratory values, and outcomes that can be expected with this ingestion to aid in its diagnosis and treatment.

\section{CASE REPORT}

A previously healthy 55-year-old male presented to the emergency department (ED) complaining of nausea and vomiting. He had picked wild mushrooms 1 week previously, searching for chanterelles and matsutake (pine) mushrooms. He ate 3 uncooked "pine mushrooms" in a large salad after 9:00 PM on the night prior to his admission. At 3:00 AM, he awoke with episodes of nausea, nonbloody, nonbilious emesis and abdominal pain of such a severity he sought medical assistance. He denied any other symptoms. He denied having taken any prescribed or over-thecounter medications, alcohol, or any illicit drug use.

On examination in the ED he was awake, alert, oriented, and had normal vital signs: BP 133/92 mmHg, HR 84 bpm, RR 12, temperature $95.9^{\circ} \mathrm{F}, \mathrm{O}_{2}$ saturation $98 \%$ on room air. He was vomiting intermittently. His abdominal exam was benign and otherwise nonfocal. His ED laboratory values (drawn 8 hours after ingestion) revealed a normal CBC, a chemistry panel showed a sodium of $134 \mathrm{mmol} / \mathrm{L}$, a potassium of $4.1 \mathrm{mmol} / \mathrm{L}$, a bicarbonate of $22 \mathrm{mmol} / \mathrm{L}$, a chloride of $98 \mathrm{mmol} / \mathrm{L}$, a BUN of $14 \mathrm{mg} / \mathrm{dL}$ $(5.0 \mathrm{mmol} / \mathrm{L})$, and a creatinine of $1.0 \mathrm{mg} / \mathrm{dL}(88 \mu \mathrm{mol} / \mathrm{L})$. Liver function tests were elevated, with an AST of $56 \mathrm{U} / \mathrm{L}$ (nl 9-40 U/L) and an ALT of $131 \mathrm{U} / \mathrm{L}$ (nl 14-72 U/L); alkaline phosphatase was normal at $108 \mathrm{U} / \mathrm{L}$. INR was normal at 1.06. To rule out other causes of liver injury, hepatitis A, B, C serologies and acetaminophen levels were obtained. They were ultimately negative.

The patient's nausea and vomiting resolved after treatment with IV fluids and ondansatron; he became asymptomatic 6 hours after presentation. Given his elevated liver function test results, there was concern for a possible $A$ phalloides ingestion and he was started on IV N-acetyl cysteine (per 21-hour, FDA-approved protocol), benzathine penicillin 2 million U IV every 4 hours, and milk thistle extract $50 \mathrm{mg} / \mathrm{kg}$ orally every 4 hours (obtained from a local health food store). He was admitted to the hospital for further observation.

The patient remained asymptomatic in the hospital. His lab results the next morning (hospital day 2) were significant for rising transaminases, with an AST increasing to $71 \mathrm{U} / \mathrm{L}$ and ALT increasing to $299 \mathrm{U} / \mathrm{L}$. Synthetic function remained normal, with an INR of 1.03 . His chemistry panel was notable for a BUN of $20 \mathrm{mg} / \mathrm{dL}$ (7.1 mmol/L) (up from 14) and a creatinine of $2.7 \mathrm{mg} / \mathrm{dL}(238$ $\mu \mathrm{mol} / \mathrm{L}$ ) (up from 1.0). Urinalysis showed 300 protein, $>1000$ glucose, 20 ketones, specific gravity 1.006, $8 \mathrm{RBC} / \mathrm{HPF}$, and $9 \mathrm{WBC} / \mathrm{HPF}$. A renal ultrasound was performed, which showed no evidence of structural abnormality or hydronephrosis. On hospital day 3, lab results showed an AST of $31 \mathrm{U} / \mathrm{L}$ (normal), an ALT of $175 \mathrm{U} / \mathrm{L}$ (declining), but a BUN of $35 \mathrm{mg} / \mathrm{dL}(12.5 \mathrm{mmol} / \mathrm{L})$ and a creatinine of $6.5 \mathrm{mg} / \mathrm{dL}(574 \mathrm{~mol} / \mathrm{L})$.

Given the rising renal function test results, in the face of normalizing LFTs, the possibility of $A$ smithiana ingestion became more likely. (The possibility of an orelline mushroom ingestion

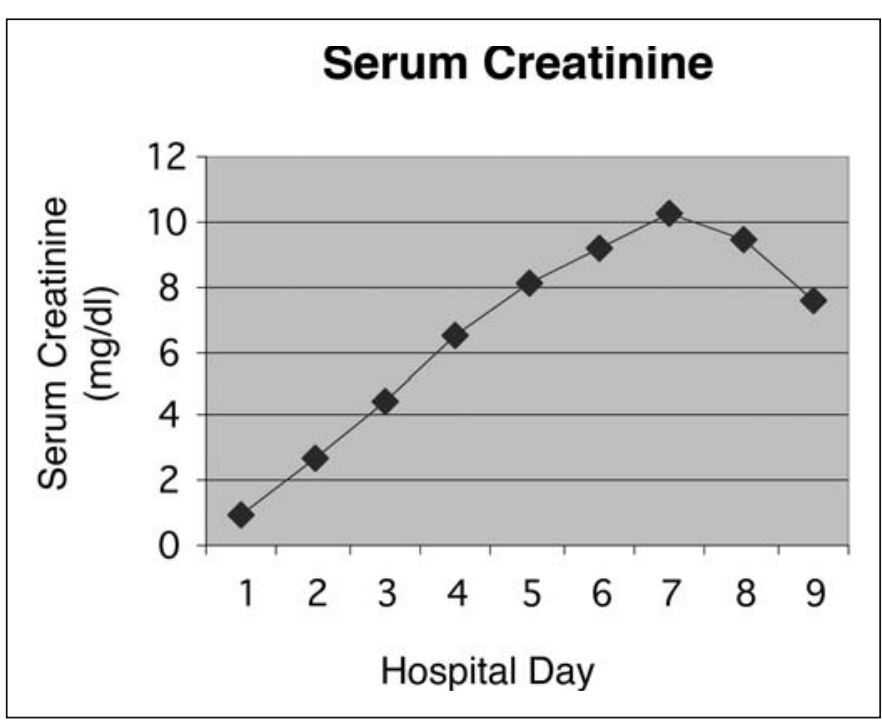

Figure 1: The patient had an initially normal creatinine level with a relatively linear rise in serum creatinine until day 7 , correlating with the elevated levels that were seen in the remainder of the case series.

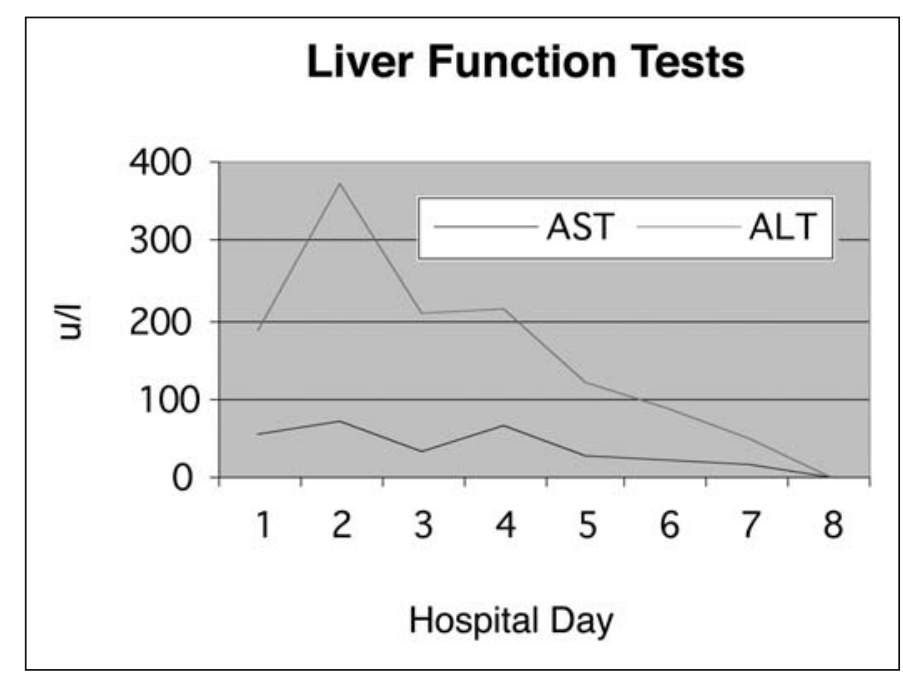

Figure 2: The patient's liver function test revealed a mild initial rise, with a return to normal after 5 days.

was discussed, but these mushrooms are not native to the Pacific Northwest.) A mycologist was able to positively identify 2 of the 3 mushrooms from the remnants: One was $A$ smithiana and the other one was Tricholoma focale (a gastrointestinal irritant mushroom). As all 3 mushrooms were collected in the same area, it is felt by the authors to be unlikely that the third was $A$ phalloides or an orelline-containing mushroom, as they are not native to the same environments as A smithiana, matsutake or chanterelles.

The patient's renal function worsened during the hospital stay (Figure 1). Hemodialysis was started 4 days after admission via a tunneled dialysis catheter. His liver function levels had returned to normal by 7 days postingestion (Figure 2), and aside 


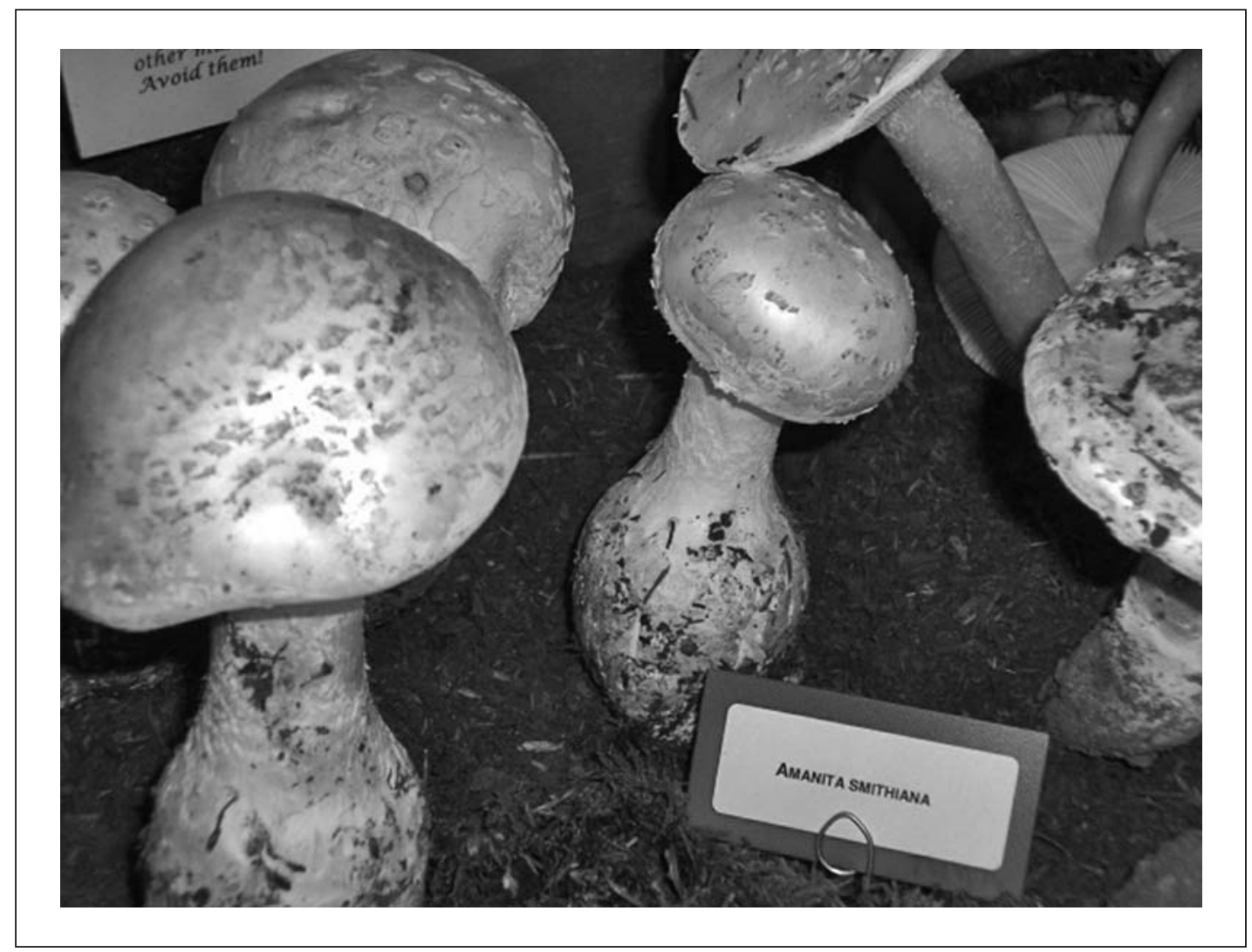

Figure 3: Amanita smithiana. Photo by Patrick West.

from his renal function and a single LDH noted to be elevated, no other lab abnormalities appeared. He continued to generate urine while an inpatient. He was discharged from the hospital 10 days postingestion on outpatient dialysis. The patient continued to have thrice-weekly outpatient dialysis. He was started on amlodipine $10 \mathrm{mg}$ daily for hypertension secondary to the renal failure. Thirty-nine days postingestion his BUN was $26 \mathrm{mg} / \mathrm{dL}(0.92$ $\mathrm{mmol} / \mathrm{L})$, his creatinine was $1.4 \mathrm{mg} / \mathrm{dL}(123.8 \mu \mathrm{mol} / \mathrm{L})$, and dialysis was discontinued.

\section{DISCUSSION}

A smithiana is common in the conifer forests of western North America, from British Columbia, Washington, Oregon, Idaho, California, and at least one collection made in New Mexico [7]. It grows during the fall in or near rotten wood in habitats at the coast and in the mountains, where native conifers grow and where it can form a mychorrizal, or mutual relationship, with these trees. The fruiting usually ends when heavy frost or snow freezes the ground.

A smithiana is a white mushroom, but weather conditions can alter the color (Figure 3). Young specimens will have white, floccose patches of universal veil tissue on the cap and powdery fibrils on the stipe (stem), but these may wash away with rain or could be destroyed by handling. Old specimens of $A$ smithiana have a putrid odor that is not present when the mushrooms are fresh. The cap size can vary from 5 to $17 \mathrm{~cm}$ across the top. The stipe can be from 6 to $>16 \mathrm{~cm}$ long and may have a long extension that goes into rotten wood. It will taper upward from a spindle-shaped (fusiform) base and the diameter varies from about 2 to $3.5 \mathrm{~cm}$ at the apex to about 4 to $5.5 \mathrm{~cm}$ at the widest point. The stipe may bruise slightly after handling, but is still mostly white and without an obvious ring (annulus) or volva as seen on many other Amanita species.

Over the last decade in the Pacific Northwest, the emergence of a new pattern of mushroom poisoning from ingestion of A smithiana has been noted when collectors are seeking the matsutake, or pine mushroom (Tricholoma magnivelare, previously named Armillaria ponderosa). A smithiana can easily be misidentified by overconfident mushroom foragers. In all of the A smithiana poisoning cases in the Pacific Northwest, the victims thought they were eating matsutake mushrooms. The matsutake mushroom grows in the same type habitat as $A$ smithiana, but it has brown staining on the cap and stipe. A partial veil covers the young gills and leaves a ring on the stipe. Matsutake mushrooms have a strong spicy odor that is described as a cross between "Red Hots" and dirty socks. The taste is reported to be mild to somewhat sweet when raw. The base on a matsutake is always covered by gray, pumicelike soil that does not rub off.

Matsutake mushrooms were featured in the book, Matsutake Mushroom: "White" Goldrush of the 1990s, consistent with the 


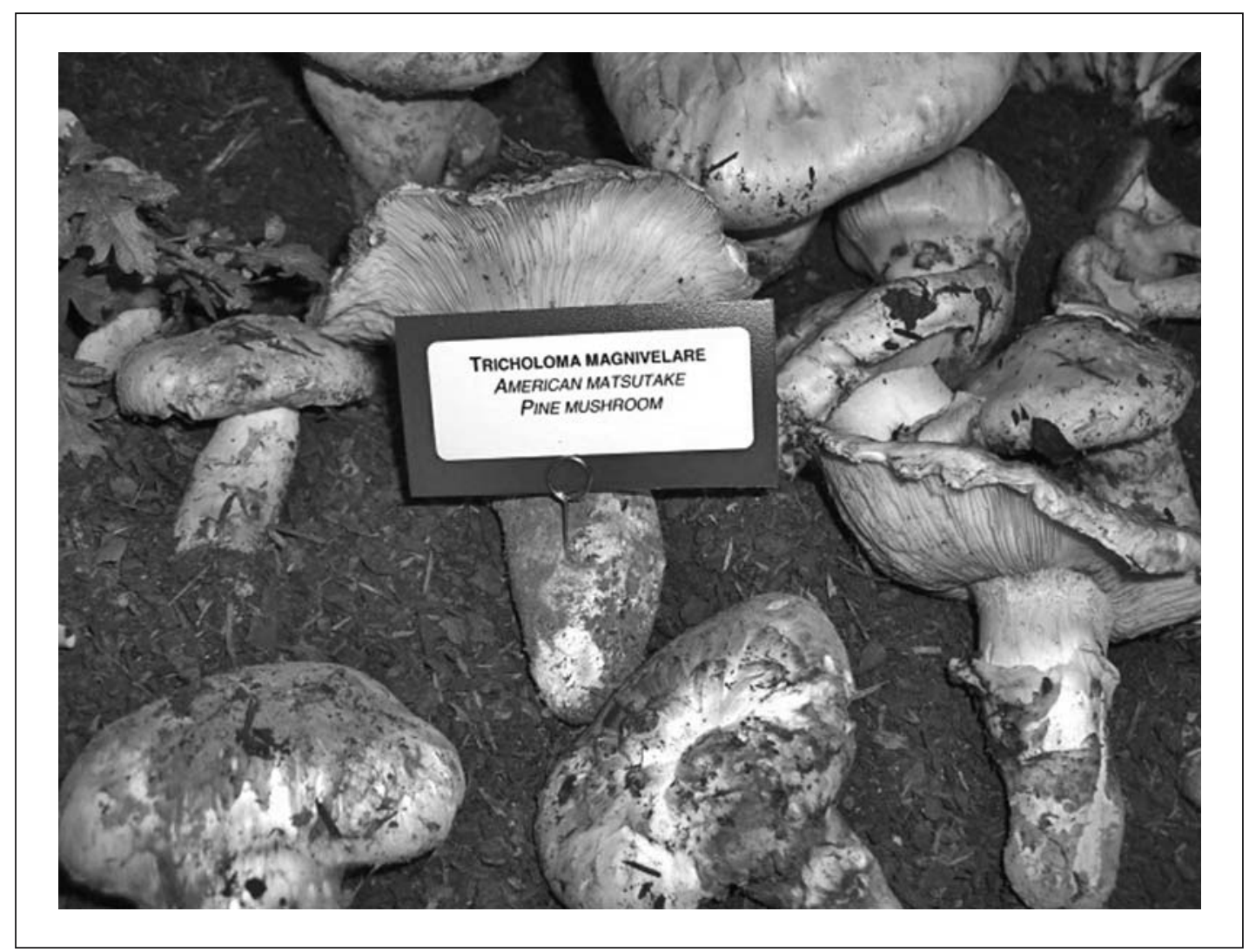

Figure 4: Tricholoma magnivelare. Photo by Patrick West.

timing of the increasing ingestion frequency that has been observed [8]. Today they typically sell for $\$ 30$ per $1 / 4 \mathrm{lb}$ and are used extensively in Japanese cooking. Since these mushrooms grow in a limited geographic range, they are frequently harvested and exported to other regions for culinary purposes [9]. Since these mushrooms have a high potential for mistaken identity and may be transported to a region with an unregulated food market, this pattern of toxicity is important to recognize as it may occur anywhere these mushrooms may be shipped. Given the large profit margin and the increased visibility of the mushroom, it is understandable that ingestions of toxic look-alike mushrooms have occurred. Cases of similar delayed onset renal failure have been described with other mushrooms, including A pseudoporphria and A abrupta [10].

A smithiana mushroom ingestions primarily cause delayed onset of renal failure without evidence of hepatic dysfunction, though to this point, the time course of the dysfunction and progression of laboratory abnormalities have not been well characterized in A smithiana, making early identification difficult. In 1964, the first case report consistent with this clinical syndrome was published, but was potentially misattributed to A phalloides, which causes primarily hepatic failure [11]. As no mycological evidence remained, the 2 cases were attributed to $A$ phalloides based solely on descriptions of the mushrooms given by the patients with the reasoning given as "only the toxins of this species and its phenotypes produce necrosis" [11]. The first case did seem to involve typical hepatic necrosis, but the second case seemed to differ from most cases of $A$ phalloides toxicity in that only reversible renal failure was observed, with a time course consistent with A smithiana ingestion [11].

In 1992, Tulloss et al. described a retrospective case series of mushroom ingestions in which renal failure seemed to be the most prominent effect [7]. In one of the cases the spores were identified as "consistent with A smithiana, but somewhat small"; a second case was noted to have good preservation of the base of the mushroom, and was positively identified as $A$ smithiana. Few details of these cases and no laboratory values were published. There have been several subsequent case reports of primarily nephrotoxic mushroom ingestions that have been theorized to be linked to the A smithiana mushroom [7]. In 1997, Leathem noted 4 cases of gastrointestinal symptoms and renal failure [12]. In one of the cases, based on presence of pungent odor of the mushroom and microscopic examination of the basal veil, stem ends were felt to be consistent with ingestions of $A$ smithiana [12]. Warden et al. described 4 cases of presumed $A$ smithiana toxicity based on a characteristic pattern of the patient's symptoms as well as the patient's description of the mushrooms [13]. No mushrooms were identified in this case series, and only the presenting laboratory values were published. The few available details from all published case reports have been summarized in Tables 1 and 2 . 


\begin{tabular}{|c|c|c|c|c|c|c|}
\hline $\begin{array}{l}\text { Reference } \\
\text { Number }\end{array}$ & $\begin{array}{c}\text { Pt Data } \\
\text { (age, sex) }\end{array}$ & $\begin{array}{l}\text { Symptom } \\
\text { Onset }\end{array}$ & Initial Symptoms & $\begin{array}{l}\text { Time to } \\
\text { Present }\end{array}$ & $\begin{array}{c}\text { BUN/Cr } \\
(\mathrm{mg} / \mathrm{dL}) /(\mathbf{m g} / \mathrm{dL})\end{array}$ & $\begin{array}{l}\text { Presenting LFTs } \\
\text { (U/L) }\end{array}$ \\
\hline \#2 [9] & $43, \mathrm{~F}$ & $2 \mathrm{hrs}$ & $\begin{array}{l}\text { urinary freq, lacrimation, } \\
\text { vomiting, oliguria }\end{array}$ & 4 days & 60/9 (estimate) & AST 21 \\
\hline \#1 [11] & $31, \mathrm{~F}$ & $8 \mathrm{hrs}$ & N/V/D/Abd pain $\times 7$ days & 6 days & $48 / 13.2$ & AST nl, ALT 105, LDH 1392 \\
\hline \#2 [11] & $49, \mathrm{M}$ & $\begin{array}{l}6 \mathrm{hrs} \text {, indig, } \\
9 \mathrm{hrs} \text { severe }\end{array}$ & $\mathrm{N} / \mathrm{V}$ & 5 days & $87 / 14.9$ & AST nl, ALT 103 \\
\hline \#3 [11] & $64, \mathrm{M}$ & $5 \mathrm{hrs}$ & $\begin{array}{c}\text { N/V/Abd pain/polyuria. } \\
\text { Anuria at day } 2\end{array}$ & 4 days & $126 / 16.29$ & AST nl, ALT 129, LDH 1924 \\
\hline \#4 [11] & $73, \mathrm{M}$ & $5 \mathrm{hrs}$ & $\begin{array}{l}\text { N/V/Abd pain/polyuria/ } \\
\text { D/sweating/dizziness }\end{array}$ & 1 day & $18 / 2.4$ & AST 223, ALT nl \\
\hline \#1 [10] & no data & $10 \mathrm{hrs} 45 \mathrm{~min}$ & Abd pain/anxiety & no data & no renal failure & no data \\
\hline \#2 [10] & no data & "within a week" & no data & no data & no renal failure & no data \\
\hline \#3 [10] & no data & $8 \mathrm{hrs}$ & $\mathrm{N} / \mathrm{V}$ & no data & $\begin{array}{l}\text { hepatic and } \\
\text { renal failure }\end{array}$ & no data \\
\hline \#4 [10] & no data & $4 \mathrm{hrs}$ & V/Abd pain, DISCHARGED & returned day 3 & renal failure & no data \\
\hline \#5 [10] & no data & $10.5 \mathrm{hrs}$ & V/D/sweats/dizzy & no data & $\begin{array}{l}\text { renal failure } \\
\text { day } 2-3\end{array}$ & no data \\
\hline \#1 [12] & $74, \mathrm{M}$ & $6 \mathrm{hrs}$ & N/V/D/anorexia/dec UOP & 6 days & $81 / 12.9$ & AST 14, ALT 33, LDH 1131 \\
\hline \#2 [12] & $74, F$ & $12 \mathrm{hrs}$ & $\begin{array}{l}\text { Abd cramps/V } \times 24 \mathrm{hrs,} \\
\text { then oliguria on day } 3-4\end{array}$ & 6 days & $91 / 12.0$ & AST 65, ALT 84, LDH 1327 \\
\hline \#3 [12] & $30, \mathrm{~F}$ & $20-30 \mathrm{~min}$ & Abd cramps/N/V & 1 day, 4 days & $72 / 12.2$ & AST 15, ALT 13, LDH 1459 \\
\hline \#4 [12] & $55, M$ & $2 \mathrm{hrs}$ & N/sweats/dizzy, V next am & 5 days & $74 / 13.9$ & AST 32, ALT 179, LDH 260 \\
\hline
\end{tabular}

Table 2: A smithiana literature review: Clinical course

\begin{tabular}{|c|c|c|c|c|}
\hline $\begin{array}{l}\text { Reference } \\
\text { Number }\end{array}$ & ID Technique & Dialysis & Length of Stay (days) & $\begin{array}{l}\text { Days until Dialysis } \\
\text { Discontinued }\end{array}$ \\
\hline \#2 [9] & description & $\begin{array}{c}\text { Peritonieal } \times 61 \text { cycles } \\
\text { over } 4 \text { days }\end{array}$ & 48 days post ingestion (44) & 48 \\
\hline \#1 [11] & description/pic & 2 sessions & 17 days post ingestion (11) & 17 \\
\hline \#2 [11] & description/pic & 4 sessions & 14 days post ingestion (9) & 37 \\
\hline \#3 [11] & stem microscopy & q 2-3 days $\times 5$ wks & 34 days post ingestion (30) & 40 \\
\hline \#4 [11] & no data & $4.5 \mathrm{wks}$ & 37 days post ingestion (36) & 180 \\
\hline \#1 [10] & no data & no & no data & no data \\
\hline \#2 [10] & A. smithina by voucher & no & no data & no data \\
\hline \#3 [10] & spores $\mathrm{c} / \mathrm{w}$, but small & $y$, unknown duration & $y$ & no data \\
\hline \#4 [10] & $+A$. smithina by researchers exam & no data & $y$ & no data \\
\hline \#5 [10] & pt identified similar mushroom & $x 6$ days & 9 days post ingestion & 9 \\
\hline$\# 1[12]$ & description & $y \times 4 w k$ & 11 days post ingestion (5) & 32 \\
\hline \#2 [12] & description & $y \times 5 w k$ & 10 days post ingestion (4) & 45 \\
\hline \#3 [12] & description & $y \times 3 w k$ & 7 days post ingestion (3) & 21 \\
\hline$\# 4[12]$ & description not Cortinarius & $y \times 4 w k$ & 8 days post ingestion (3) & 29 \\
\hline
\end{tabular}


The clinical syndrome of $A$ smithiana ingestion is a delayedonset renal toxicity, but unlike that which has been well described with certain Cortinarius, or other orellanine-containing mushrooms, in which the onset of renal failure occurs much later, often several days to a week after ingestion [10]. We feel that this is unlikely to be a Cortinarius ingestion. One prior case of a Pacific Northwest mushroom ingestion leading to renal failure was attributed to Cortinarius, as at the time it occurred it was the only known nephrotoxic mushroom (though one of the authors now feels that this attribution was in error) [14]. This case report lead to the suggestion that North American cases could be Cortinarius ingestions; however, mycologists do not consider Cortinarius orellanus to be native to the Pacific Northwest. It is also relatively easy to differentiate Cortinarius species from A smithiana, as Cortinarius species are typically orange, brown, or yellow and smaller mushrooms compared to the larger white body of A smithiana [12]. Given these differences, we feel it would be unlikely that an experienced mushroom hunter would mistake the two. The general time course described for Cortinarius symptoms is different than described for A smithiana cases. In the largest review of Cortinarius cases, the onset of gastrointestinal symptoms occurred later, at 12 hours to 14 days after ingestion, with a mean of 3 days after ingestion [15]. Renal failure also occurs later with Cortinarius, varying from 4 to 15 days after ingestion, with a median of 8.5 days [15].

The purported toxin isolated from $A$ smithiana is allenic norleucine (amino-hexadienoic acid) [16]. When injected intraperitoneally to guinea pigs, allenic norleucine showed renal toxicity consistent with $A$ smithiana, with lethal dose being $100 \mathrm{mg} / \mathrm{kg}$ body weight [17]. Identical microscopic changes were noted in 3 cell lines of renal tubular epithelium when cultured with either A smithiana extract or synthetic allenic norleucine [18]. Allenic norleucine caused renal epithelial necrosis, whereas nonallenic norleucine did not, giving rise to the belief that it is most likely the unsaturated C-terminus of the allenic norleucine that causes toxicity in A. smithiana. The allenic norleucine was shown to begin affecting the cultures' epithelial cells within 12 hours, consistent with the time course of $A$ smithiana ingestion. Renal tubular epithelium cultured with orellanine did not begin to have effects until 24 hours after incubation. Orelline affected the renal cell lines in a different pattern than did the $A$ smithina extract and the allenic norleucine, indicating a different toxin. Of note, when incubated with glutathione, the allenic norleucine was not prevented from damaging the renal epithelium, which may indicate little role for NAC as a therapy for this ingestion.

In Myler's report, the case consistent with $A$ smithiana had a renal biopsy performed 43 days after ingestion [11]. Electron microscopy of the biopsy specimens showed diffuse interstitial fibrosis without inflammatory changes. Both distal and proximal tubules appeared to be dilated and contained cellular debris, and brush borders of the glomeruli appeared to be disrupted, all findings consistent with tubular necrosis.

A similar pattern of delayed-onset renal insufficiency has been noted with other mushrooms in Europe and Asia. In France, a review from the Marseille Poison Center showed that ingestion of the A proxima mushroom causes a similar type of renal syndrome. It is often mistaken for the nontoxic $A$ ovoidea mushroom. Their cases present with what appears to be a somewhat more delayed onset of GI symptoms, on average 13 hours after ingestion, versus the 5 hours we observed [19]. Fourteen out of 31 patients in their series developed renal failure and 10 patients developed hepatic injury. Eleven of the 14 patients with renal insufficiency required dialysis, and all recovered renal function, similar to the cases of $A$ smithina [19]. There have also been similar reports of other mushrooms causing a similar syndrome in Japan [10]. The mushrooms A pseudoporphyria and $A$ abrupta have been shown to contain the allenic norleucine toxin, which causes renal injury. Further investigation is required to determine if allenic norleucine is present in A proxima [10].

Our case shows a pattern that is consistent with the few other A smithiana cases from the literature, and provides increased information about the toxic progression of $A$ smithiana ingestion (Tables 1 and 2). We positively identified $A$ smithiana as the ingestion, which has been accomplished infrequently in cases from the literature. Our patient's early presentation, along with our subsequent positive identification of $A$ smithiana by a mycologist early in his clinical course, allowed us the opportunity to initiate treatments to try to prevent renal failure. We also had the opportunity to obtain serial laboratory values and describe the evolution of a confirmed $A$ smithiana ingestion, which has not been documented previously.

Our case and an analysis of all case reports demonstrate several key features in the presentation of $A$ smithiana poisoning. First, the range of onset of symptoms runs from 20-30 minutes to 12 hours after ingestion, with the median onset being in the 5to 6-hr range. The initial presenting symptoms typically involve nausea, vomiting, and abdominal pain, with little of the diarrhea that is typically described with $A$ phalloides ingestions. Early onset of gastrointestinal symptoms after mushroom ingestion poisonings are typically considered to be reassuring of a benign ingestion, with gastrointestinal symptoms delayed 6 hours or longer used to differentiate $A$ phalloides from less toxic mushroom ingestions $[20,21]$. The review of cases from the literature suggests that $A$ smithiana poisoning could cause symptoms earlier than 6 hours postingestion in many cases. Mushroom ingestion causing early GI toxicity are common and are often managed with only supportive care, thus early identification of $A$ smithiana ingestion has been missed (as was one of the early presenters in the literature). Our case also exemplified another possible explanation for the observed early onset of gastrointestinal symptoms: that foragers frequently ingest a mixture of mushrooms, with a GI toxic mushroom causing the early symptoms and obscuring the true onset of the later $A$ smithiana toxicity. Even with this possibility, there does seem to be a trend of early GI toxicity noted in our case and the other cases of $A$ smithiana in the literature, possibly providing an early warning sign for $A$ smithiana ingestion.

Our review also revealed that patient presentation is bimodal, as 4 cases (including our case) presented on day 1, with the majority presented 3-6 days after ingestion. Our case combined with the one other case of renal toxicity that presented on day 1 
suggests that in early presentation, transient mild liver injury occurs, which has been previously demonstrated with single laboratory values, resolves quickly, as the liver function tests normalize by 1 week after ingestion. In review of the literature, LDH elevation does appear to be a significant marker for toxicity. Our case had only 1 value for $\mathrm{LDH}$, which was elevated on day 2. Based on this and the single values in the literature, no conclusion can be made on the time course of these values. Renal failure may not be evident on early laboratory evaluation, though it seems to rise in a predictable manner as the clinical course progresses.

The renal failure observed in these patients does seem to be largely reversible with supportive care and hemodialysis. Dialysis in our review was required for between 2 and 5 weeks. Patients required an admission of between 3 to 44 days, with a mean admission time of 15.5 days. With support of dialysis, renal function universally seems to return to a level not requiring dialysis after a range of 9 to 48 days, with a mean of 31.4 days after ingestion.

\section{CONCLUSIONS}

A smithiana mushroom ingestions have occurred uniquely in Oregon, Washington and British Columbia. Onset of symptoms may occur earlier than the 6-hr onset used for triaging Amanita phalloides cases, and a review of the literature showed the mean time to onset was 5 hours, similar to the case presented here. Renal failure develops over 3 to 5 days, in contrast to the other nephrotoxic orellanine-containing mushroom species ingestions that develop renal failure over a longer period of time. Treatment is supportive, including maintenance of renal perfusion with normalization of volume and hemodialysis for treatment of renal failure. Recovery can be expected with aggressive support, and hemodialysis may be discontinued after several weeks when creatinine returns to normal and urine output returns.

The authors have no potential financial conflicts of interest to report.

\section{REFERENCES}

1. Watson W, Litovitz T, Klein-Schwartz W, et al. 2003 Annual report of the American Association of Poison Control Centers Toxic Exposure Surveillance System. Am J Emerg Med 2004;22:335-404.

2. Watson W, Litovitz T, Rodgers G, et al. 2004 Annual report of the American Association of Poison Control Centers Toxic Exposure Surveillance System. Am J Emerg Med 2005;23: 589-666.

3. Lai M, Klein-Schwartz W, Rodgers G, et al. 2005 Annual report of the American Association of Poison Control Centers' National Poisoning and exposure database. Clin Tox (Phila) 2006;44:803-932.
4. Bronstein A, Spyker D, Cantilena L, et al. 2006 Annual report of the American Association of Poison Control Centers National Poison Center Database (NPDS). Clin Tox 2007;45: 815-917.

5. Klein A, Hart J, Brems J, et al. Amanita poisoning: treatment and the role of liver transplantation. Am J Med 1989;86: 187-193.

6. Broussard C, Aggarwal A, Lacey S, et al. Mushroom Poisoning_From Diarrhea to Liver Transplantation. Am J Gastroenterol 2001;96(11):3195-3198.

7. Tuloss R, Lindgren J. Amanita smithiana: taxonomy, distributions, and poisonings. Mycotaxon 1992;45:373-387.

8. Guin J. Matsutake Mushroom: The White Goldrush of the 1990s: A Guide and Journal. Happy Camp, CA: Naturegraph Publishers, 1997.

9. Chou H. Fantastic Forage. Wild matsutake mushrooms. Seattle Post-Intelligencer. Oct 13, 2004.

10. Saviuc P, Danel V. New syndromes in Mushroom Poisoning. Toxicol Rev 2006;25(3):199-209.

11. Myler R, Lee J, Hopper J. Renal tubular necrosis caused by mushroom poisoning. Ann Intern Med 1964;114:196-204.

12. Leathem A, Purssell R, Chan V, et al. Renal failure caused by mushroom poisoning. J Toxicol/Clin Toxicol 1997;35:67-75.

13. Warden C, Benjamin D. Acute renal failure associated with suspected Amanita smithiana ingestions: A case series. Acad Emerg Med 1998;5:808-812.

14. Moore B, Burton BT, Lindgren J, et al. Cortinarius mushroom poisoning resulting in renal failure. Vet Human Tox 1991; 33:369.

15. Danel C, Saviuc P, Garon D. Main features of Cortinarius spp. Poisoning: a literature review. Toxicon 2001;(39):1053-1060.

16. Chilton WS, Ott J. Toxic metabolites of Amanita panterina, A. cothurnata, A. muscarina, and other Amanita species. Lloydia 1976;39(2-3):150-157.

17. Chilton W, Decato L, Malone M. The unsaturated norleucines of Amanita solitaria, chemical and pharmacologic studies. Lloydia 1973;36:169-173.

18. Pelizzari V, Feifel E, Rohrmoser M, et al. Partial purification and characterization of a toxic component of Amanita smithiana. Mycologia 1994;86:555-560.

17. Enjalbert F, Rapior S, Jouguier-Soule J, et. al. Treatment of amatoxin poisoning: 20-year retrospective analysis. Clin Tox 2002; 40(6): 715-757.

19. de Haro L, Jouglard J, Arditti J, et al. Acute renal insufficiency caused by Amanita proxima poisoning: Experience of the Poison Center of Marseille Nephrologie 1998;19(1):21-24.

20. Goldfrank L. Mushrooms. In: Flomenbaum N, Goldfrank L, Hoffman R, Howland M, Lwein N, Nelson L, editors. Goldfrank's Toxicologic Emergencies. 8th ed. New York: McGraw-Hill; 2006, pp. 1564-1576.

21. Marquardt K. Mushrooms. In: Olson K, editor. Poisoning \& Drug Overdose. 5th ed. New York: McGraw-Hill. 2007, pp. 275-276. 